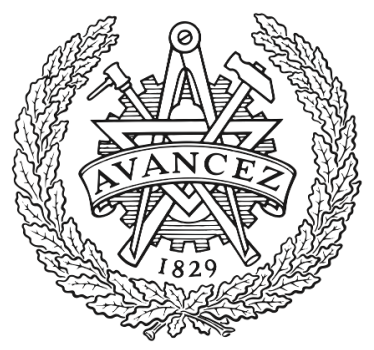

CHALMERS

UNIVERSITY OF TECHNOLOGY

\title{
Chemical Doping of Conjugated Polymers with the Strong Oxidant Magic Blue
}

Downloaded from: https://research.chalmers.se, 2023-04-26 12:24 UTC

Citation for the original published paper (version of record):

Hofmann, A., Kroon, R., Zokaei, S. et al (2020). Chemical Doping of Conjugated Polymers with the Strong Oxidant Magic Blue. Advanced Electronic Materials, 6(8).

http://dx.doi.org/10.1002/aelm.202000249

N.B. When citing this work, cite the original published paper. 


\title{
Chemical Doping of Conjugated Polymers with the Strong Oxidant Magic Blue
}

\author{
Anna I. Hofmann, Renee Kroon, Sepideh Zokaei, Emmy Järsvall, Claudia Malacrida, \\ Sabine Ludwigs, Till Biskup, and Christian Müller*
}

\begin{abstract}
Molecular doping of organic semiconductors is a powerful tool for the optimization of organic electronic devices and organic thermoelectric materials. However, there are few redox dopants that have a sufficiently high electron affinity to allow the doping of conjugated polymers with an ionization energy of more than $5.3 \mathrm{eV}$. Here, p-doping of a broad palette of conjugated polymers with high ionization energies is achieved by using the strong oxidant tris(4bromophenyl)ammoniumyl hexachloroantimonate (Magic Blue). In particular diketopyrrolopyrrole (DPP)-based copolymers reach a conductivity of up to $100 \mathrm{~S} \mathrm{~cm}^{-1}$ and a thermoelectric power factor of $10 \mu \mathrm{W} \mathrm{m} \mathrm{m}^{-1} \mathrm{~K}^{-2}$. Further, both electron paramagnetic resonance (EPR) as well as a combination of spectroelectrochemistry and chronoamperometry is used to estimate the chargecarrier density of the polymer PDPP-3T doped with Magic Blue. A molar attenuation coefficient of $6.0 \pm 0.2 \times 10^{3} \mathrm{~m}^{2} \mathrm{~mol}^{-1}$ is obtained for the first polaronic sub-bandgap absorption of electrochemically oxidized PDPP-3T. Comparison with chemically doped PDPP-3T suggests a charge-carrier density on the order of $10^{26} \mathrm{~m}^{-3}$, which yields a charge-carrier mobility of up to $0.5 \mathrm{~cm}^{2} \mathrm{~V}^{-1} \mathrm{~s}^{-1}$ for the most heavily doped material.
\end{abstract}

\section{Introduction}

Semiconducting polymers attract wide attention as a class of materials that may enable the development of flexible and biocompatible electronic devices, pushing the boundaries of electronics

Dr. A. I. Hofmann, Dr. R. Kroon, S. Zokaei, E. Järsvall, Prof. C. Müller Department of Chemistry and Chemical Engineering

Chalmers University of Technology

Göteborg 41296, Sweden

E-mail: christian.muller@chalmers.se

C. Malacrida, Prof. S. Ludwigs

IPOC-Functional Polymers

Institute of Polymer Chemistry

Stuttgart 70569, Germany

Dr. T. Biskup

Physical Chemistry and Didactics of Chemistry

University of Saarland

Saarbrücken 66123, Germany

The ORCID identification number(s) for the author(s) of this article can be found under https://doi.org/10.1002/aelm.202000249.

(C) 2020 The Authors. Published by WILEY-VCH Verlag GmbH \& Co. $\mathrm{KGaA}$, Weinheim. This is an open access article under the terms of the Creative Commons Attribution-NonCommercial License, which permits use, distribution and reproduction in any medium, provided the original work is properly cited and is not used for commercial purposes.

DOI: 10.1002/aelm.202000249 toward applications that cannot be targeted with inorganic materials alone..$^{[1-4]}$ The opto-electronic as well as the mechanical properties of semiconducting polymers depend strongly on the charge-carrier density, which can be tuned chemically or electrochemically, a process which is referred to as doping. Hence, doping is a powerful tool to optimize the performance of organic electronic devices, such as transistors, solar cells and organic light-emitting diodes (OLEDs) $)^{[1,5]}$ as well as of organic thermoelectric materials. ${ }^{[6-8]}$ Further, in case of electrochemical transistors and light-emitting electrochemical cells, modulation of the charge-carrier density is essential to the operation of these devices..$^{9,10]}$

One way to introduce charges is via redox doping, also referred to as molecular doping, which involves an electron transfer between the semiconducting polymer and a small molecule, the socalled redox dopant. In case of p-doping a positive energetic offset between the electron affinity (EA) of the small-molecular dopant and the ionization energy (IE) of the semiconducting polymer is advantageous, i.e., $\mathrm{EA}_{\mathrm{dopant}}>$ $\mathrm{IE}_{\text {polymer }}$ Depending on the relative position of the energy levels one or even two electrons can be transferred from the polymer backbone to a dopant molecule. ${ }^{[1]]}$

A broad variety of $\mathrm{p}$ - and n-type polymer-dopant couples have been studied. The most common p-type redox dopant is 2,3,5,6-tetrafluoro-7,7,8,8-tetracyanoquinodimethane (F4TCNQ), ${ }^{[12,13]}$ which shows an electron affinity of $\mathrm{EA} \approx 5.2 \mathrm{eV}$ and readily oxidizes polymers such as poly(3-hexylthiophene) (P3HT; IE $\approx 5.1 \mathrm{eV})^{[14-19]}$ and thiophene-thienothiophene copolymers (PBTTT; IE $\approx 5.2 \mathrm{eV}$ ). ${ }^{[20,21]}$ Many other conjugated polymers such as, for example, high-mobility donor-acceptor polymers have an IE of more than $5.3 \mathrm{eV}$ and can therefore not be doped with F4TCNQ. At the same time, doping of high mobility polymers is of special interest in the field of organic thermoelectrics, because the use of such polymers may allow to increase the thermoelectric power factor, which scales with the electrical conductivity and hence charge-carrier mobility. ${ }^{[22,23]}$ There are only few examples of dopants with a high electron affinity including 1,3,4,5,7,8-hexafluoro-tetracyano-naphthoquinodimethane (F6TCNNQ) $(\mathrm{EA} \approx 5.3 \mathrm{eV}),{ }^{[11,24]}$ hexacyano-trimethylene-cyclopropane $(\mathrm{EA} \approx 5.9 \mathrm{eV})^{[24]}$ and its derivatives, ${ }^{[25]}$ and molybdenum dithiolene complexes such as $\mathrm{Mo}\left(\mathrm{tfd}-\mathrm{COCF}_{3}\right)_{3}$ 


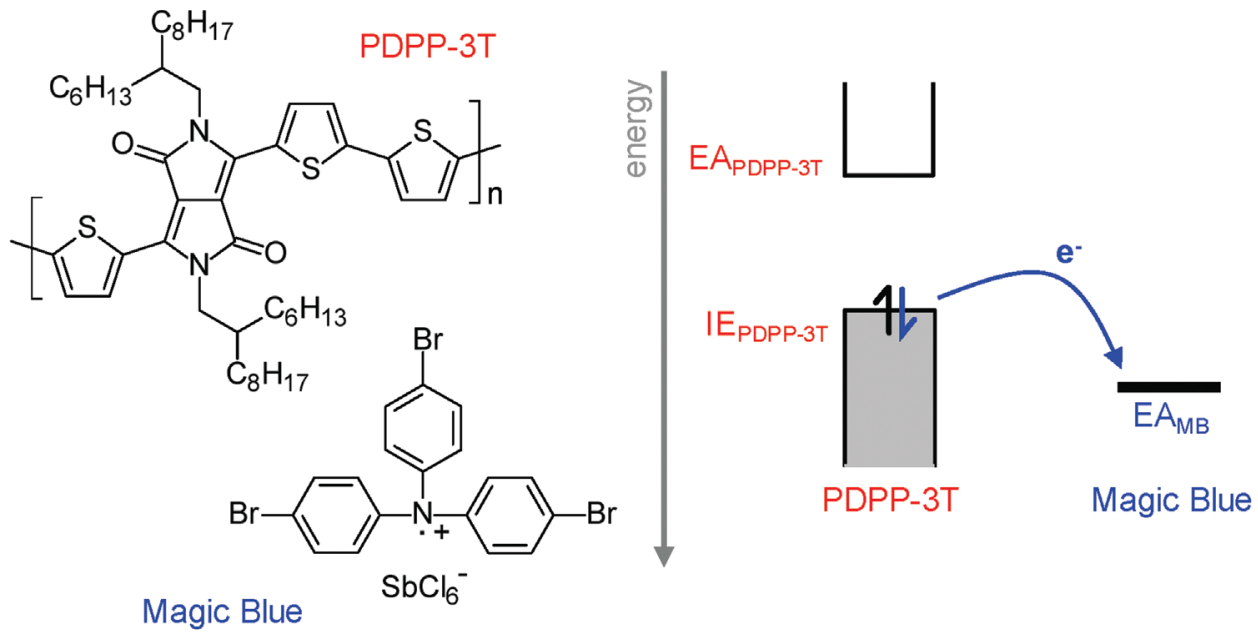

Figure 1. Chemical structure of PDPP-3T and Magic Blue (MB) and illustration of electron transfer from PDPP-3T to the tris (4-bromophenyl)ammoniumyl radical cation of $\mathrm{MB}$.

$(\mathrm{EA} \approx 5.5 \mathrm{eV}) \cdot{ }^{[26-28]}$ These redox agents allow p-doping of not only P3HT, but also diketopyrrolopyrrole (DPP) based copolymers with an IE of about $5.4 \mathrm{eV} \cdot{ }^{[24,29,30]}$ While the electron affinities quoted here are suitable for an approximate comparison with the IE of the donor material, it is important to keep in mind that their absolute value can strongly vary depending on the degree of electrostatic interactions with the semiconductor host. ${ }^{[31]}$

To expand the palette of possible p-type redox dopants suitable for conjugated polymers with an IE larger than $5.3 \mathrm{eV}$, we here study doping with tris(4-bromophenyl)ammoniumyl hexachloroantimonate, also known as Magic Blue (MB) due to its deep blue color (see Figure 1 for chemical structure). Magic Blue is a strong one-electron oxidant with an EA of $5.8 \mathrm{eV}\left(0.7 \mathrm{~V} \text { versus } \mathrm{Fc} / \mathrm{Fc}^{+}\right)^{[32}$ that is widely used in organic chemistry as a stoichiometric and catalytic oxidant due to its good stability in air. Furthermore, it has been employed to dope transition-metal dichalcogenides, ${ }^{[32]}$ graphene, ${ }^{[33]}$ and hole-injection layers in OLEDs. ${ }^{[34-36]}$

We demonstrate that MB can be used as a cost-effective dopant for a range of common p-type polymers with a high ionization energy. Upon doping with MB most polymers displayed intense polaronic absorption features, while their maximum electrical conductivity ranged from $10^{-2}$ to $10^{2} \mathrm{~S} \mathrm{~cm}^{-1}$ giving rise to a thermoelectric power factor between $10^{-1}$ to $10^{1} \mu \mathrm{W} \mathrm{m} \mathrm{m}^{-1} \mathrm{~K}^{-2}$. Both, electron paramagnetic resonance (EPR) as well as a combination of spectroelectrochemistry and chronoamperometry are used to estimate a charge-carrier density on the order of $10^{26} \mathrm{~m}^{-3}$ for a DPP polymer that was strongly doped with MB.

\section{Results and Discussion}

In a first set of experiments we examined doping of the polymer PDPP-3T with an IE $\approx 5.4 \mathrm{eV}$ (Figure 1). We observe the emergence of pronounced polaronic absorption peaks upon doping with $\mathrm{MB}$, with the P2 peak located at $\lambda_{P 2} \approx 1220 \mathrm{~nm}$ (Figure 2a) and a second P1 absorption in the far-infrared (Figure S1, Supporting Information). It is interesting to note that doping with MB does not give rise to additional absorption features in the visible spectrum other than polaronic features, in contrast to other redox dopants such as F4TCNQ. Electron transfer from the polymer to the tris(4-bromophenyl)ammoniumyl radical cation of $\mathrm{MB}$ results in neutral tris(4-bromophenyl)amine, which is
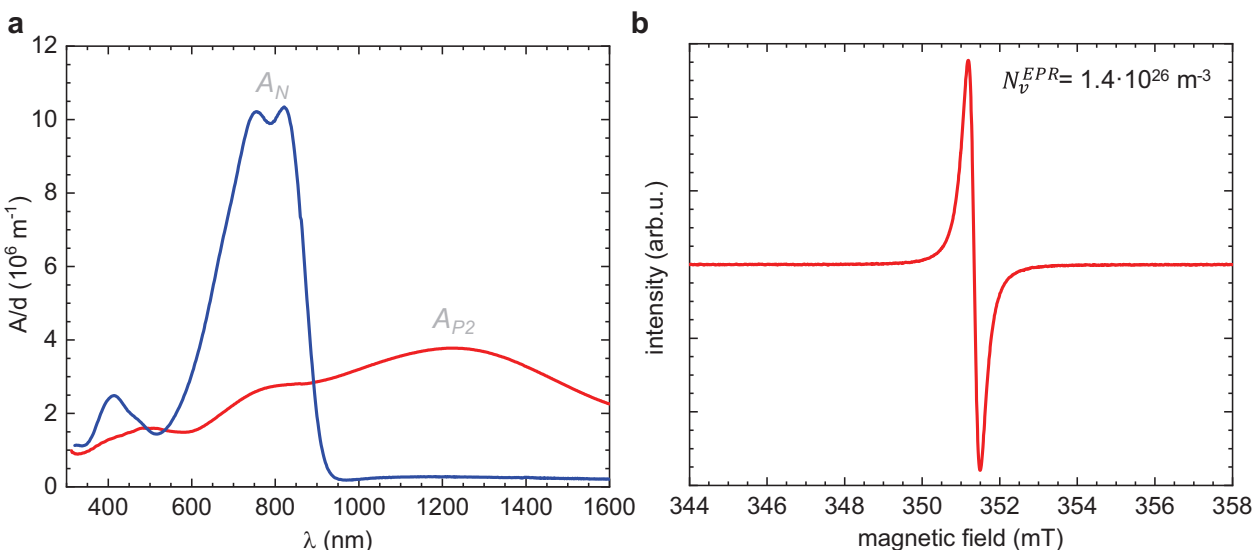

Figure 2. a) UV-vis spectrum of a $149 \mathrm{~nm}$ thin PDPP-3T film showing only absorbance by the neat polymer $A_{N}$ (blue), and a $126 \mathrm{~nm}$ thin PDPP-3T film sequentially doped with $\mathrm{MB}$, dominated by the polaronic absorbance $A_{P 2}$ (red) and b) EPR spectrum of the same doped PDPP-3T film. 
optically transparent in the visible and near infrared spectrum. The hexachloroantimonate anion $\mathrm{SbCl}_{6}^{-}$is unaffected by the redox reaction and serves as the counter ion for the oxidized polymer. Potentiodynamic spectroelectrochemistry measurements of PDPP-3T reveal a clear isosbestic point, which indicates that even in case of highly doped polymer only one absorbing species is present, i.e., polarons (Figure S2, Supporting Information). EPR spectroscopy of MB doped PDPP-3T reveals a distinct signal at $g=2.003$ (Figure $2 \mathrm{~b}$ ), which we assign to the hole polaron. We estimate a charge-carrier density of $N_{v}^{E P R} \approx(1.4 \pm 0.3) \cdot 10^{26} \mathrm{~m}^{-3}$ by counting the number of free spins. To rule out that preferential in-plane orientation of the polymer within the film influences our spin quantification, we recorded angular-dependent EPR spectra (Figure S3, Supporting Information). Only a very weak orientation dependence of the doped polymer film can be detected, different to other doped polymers. Furthermore, the intensity of the EPR signal does not depend on the orientation of the film, greatly facilitating the quantification of the EPR signal.

We were interested in developing an independent method to assess $N_{v}$ of MB doped PDPP-3T. To obtain an estimate for the molar attenuation coefficient $\varepsilon_{P 2}$ of the hole polaron we chose to combine two established characterization methods, spectroelectrochemistry ${ }^{[30,37-39]}$ and chronoamperometry (Figure 3). ${ }^{[40-42]}$ The electrochemical cell comprised a polymer film with a thickness of $d \approx 140 \mathrm{~nm}$ spin-cast onto an ITO/glass working electrode, a Pt wire counter electrode and a Ag wire pseudoreference electrode, which were submerged in an electrolyte solution of $0.1 \mathrm{M} \mathrm{TBAPF}_{6}$ in acetonitrile (AcN; cf. Experimental for details). Before each measurement, the film was reduced at a negative potential of $-0.52 \mathrm{~V}$ (cf. Figure $3 \mathrm{a}$ ). Then, a chronoamperometry measurement was carried out: upon application of a static positive potential the polymer film was oxidized to a certain extent, which gives rise to a transient current $I(t)$ (Figure 3b). By integrating the transient current over time, we calculated the total number of charges $Q$

$Q=\int_{t=0}^{\infty} I(t) \mathrm{d} t$

The electrochemical oxidation of the polymer introduces hole polarons; electrons are extracted via the working electrode and overall charge neutrality is maintained through the influx of $\mathrm{PF}_{6}^{-}$counterions from the electrolyte. To obtain the charge density $Q_{u}$, the amount of charge was normalized with regard to the sample volume in contact with the electrolyte. After completion of the oxidation reaction a UV/Vis spectrum was recorded (Figure 3c), and the thickness-normalized absorbance $A_{P 2} / d$ at the peak wavelength of the P2 polaron peak was extracted. We then estimated the molar attenuation coefficient $\varepsilon_{P 2}$ from the slope of $A_{P 2} / d$ versus $Q_{v}$ (Figure 3d), assuming that only polarons are present (Figure $\mathrm{S} 2$, Supporting Information). We obtain $\varepsilon_{P 2} \approx(6.0 \pm 0.2) \cdot 10^{3} \mathrm{~m}^{2} \mathrm{~mol}^{-1}$ for PDPP-3T, which is comparable to $\varepsilon_{P 2}$ reported for other DPP based copolymers. ${ }^{[43]}$
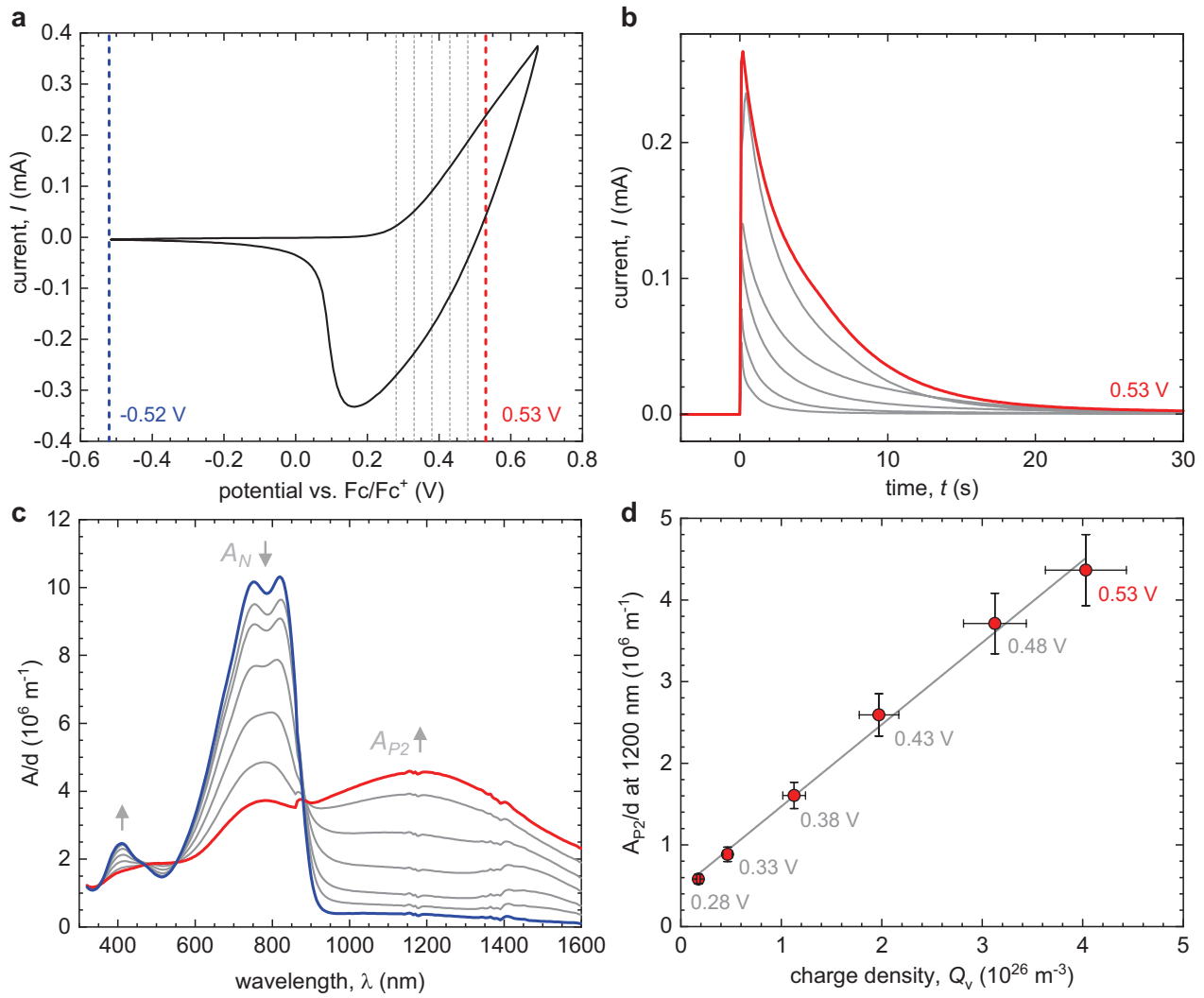

Figure 3. a) Cyclic voltammogram of PDPP-3T; b) electrochemical transient currents and c) UV/Vis absorption spectra recorded at different constant electrochemical potentials; and d) the thickness-normalized absorbance $A_{P 2} / d$ at $1200 \mathrm{~nm}$ versus the charge density $Q_{v}$ calculated by integration of the electrochemical transient currents, and normalized with regard to the sample volume. 
To estimate the charge-carrier density $N_{v}$ of chemically doped PDPP-3T we compared the absorbance $A_{P 2}$ of the first subbandgap polaronic absorption peak P2 with the molar attenuation coefficient $\varepsilon_{P 2}$, obtained from electrochemical doping, by using the Beer-Lambert law

$A_{P 2}=\varepsilon_{P 2} \cdot d \cdot N_{v}$

We note that the exact position and oscillator strength of the polaronic absorption depends on the distance between the hole polaron on the polymer and the anion. ${ }^{[18,44]}$ For chemical doping of PDPP-3T with MB the P2 peak wavelength $\lambda_{P 2}$ is located at $1220 \mathrm{~nm}$, whereas in case of electrochemically oxidized material $\lambda_{P 2} \approx 1180 \mathrm{~nm}$ (Figures $2 \mathrm{a}$ and $3 \mathrm{c}$ ). We propose that these differences arise due to the slightly larger anion thermochemical radius $r$ of $\operatorname{SbCl}_{6}^{-}(r=3.3 \AA)$ as compared to $\operatorname{PF}_{6}^{-}(r=2.4 \AA),{ }^{[45]}$ which likely leads to a slight difference in the average polaronanion distance. ${ }^{[27]}$ Since we only observe a minor difference in $\lambda_{P 2}$ for chemically and electrochemically doped PDPP-3T, we deem that a comparison of the two types of spectra does not introduce a significant error. In agreement, a number of studies have found that, qualitatively, the UV/Vis spectra of chemically and electrochemically doped polymers have a similar position and shape. ${ }^{[30,37,38]}$ We argue that the counterions with a similar thermochemical radius give rise to energetically similar optical transitions. Our comparison with electrochemically oxidized samples indicates a charge-carrier density of $N_{v}^{U V / V i s} \approx$ $(3.4 \pm 0.3) \cdot 10^{26} \mathrm{~m}^{-3}$ for MB doped PDPP-3T, which is in reasonable agreement with the value of $N_{v}^{E P R} \approx(1.4 \pm 0.3) \cdot 10^{26} \mathrm{~m}^{-3}$ extracted for the same sample by EPR (Figure 2), and typical for highly doped conjugated polymers. ${ }^{[20,46,47]}$

Sequential doping of PDPP-3T by immersion in a solution of $\mathrm{MB}$ in $\mathrm{AcN}: \mathrm{CHCl}_{3}$ resulted in an electrical conductivity of up to $40 \mathrm{~S} \mathrm{~cm}^{-1}$ (Figure S4, Supporting Information), which was stable at ambient conditions for 1-2 days, but gradually decreased over longer periods of time, e.g. to about $50 \%$ of the original value after 30 days, which we tentatively explain with prolonged exposure to air (Figure S4, Supporting Information). We estimate the charge-carrier mobility $\mu$ according to

$\sigma=N_{v}^{U V / V i s} \cdot e \cdot \mu$

where $e$ is the elemental charge. For different degrees of doping we obtain a mobility in the range of $0.009-0.5 \mathrm{~cm}^{2} \mathrm{~V}^{-1} \mathrm{~s}^{-1}$ (Table 1). The same polymer shows a hole mobility of up to $0.3 \mathrm{~cm}^{2} \mathrm{~V}^{-1} \mathrm{~s}^{-1}$ when used as the channel material of field-effect transistors. ${ }^{[48]}$
In a further set of experiments, we examined if other conjugated polymers with a high IE can be doped with MB. We chose to study different families of structurally similar materials including carbazole, cyclopentadithiophene, fluorene, quinoxaline, DPP and dithienobenzene based copolymers as well as poly(p-phenylene vinylene) (PPV) derivatives (see Figure 4 and Figure S5 (Supporting Information) for chemical structures). In addition, we included regioregular P3HT (regioregularity $\approx$ $88 \%)$ as a reference material.

Upon treatment with MB all polymers, except F8BT, showed pronounced sub-bandgap absorption features in the infrared (Figure 4; Figure S5, Supporting Information). For all doped polymers the sub-bandgap absorption consisted of a distinct P2 absorption peak below $1500 \mathrm{~nm}$, together with a further P1 absorption feature in the far-infrared. The presence of polarons confirms electron transfer between $\mathrm{MB}$ and the various donor polymers. We rationalize the absence of any sub-bandgap absorption in F8BT with the inability of $\mathrm{MB}$ to dope the polymer due to its too high $\mathrm{IE}_{\mathrm{F} 8 \mathrm{BT}} \approx 5.9 \mathrm{eV}$. Instead, for all other polymers $\mathrm{EA}_{\mathrm{MB}}>\mathrm{IE}_{\text {polymer }}$ and hence electron transfer readily occurs (Figure 1).

The doped films displayed conductivities in the range of 0.03 to $101 \mathrm{~S} \mathrm{~cm}^{-1}$, with PCPDTBT being the least conducting sample with $\sigma \approx 0.03 \mathrm{~S} \mathrm{~cm}^{-1}$, and PCDTBT, PDPP-TT and PDPP-ene being the champion materials, displaying conductivities between 55 and $101 \mathrm{~S} \mathrm{~cm}^{-1}$ (Table 2). For P3HT we measure a high conductivity of $26 \mathrm{~S} \mathrm{~cm}^{-1}$ upon doping with $\mathrm{MB}$, which is on a par with values reported for P3HT doped with Mo(tfd$\left.\mathrm{COCF}_{3}\right)_{3} \cdot{ }^{[28]}$ For the same batch of P3HT doped with F4TCNQ we find a conductivity of $0.8 \mathrm{~S} \mathrm{~cm}^{-1}$, which is slightly lower than previous results for P3HT with a similar regioregularity. ${ }^{[15]}$

For an in-depth study of the thermoelectric properties we chose to focus on the polymers that reach a conductivity of $\sigma>20 \mathrm{~S} \mathrm{~cm}^{-1}$. More specifically, we compared PCDTBT, F8DTBT, and F8T2, two of them containing a benzothiadiazole unit and two of them a polyfluorene unit, as well as different DPP derivatives. TQ1 and P3HT were added as reference materials. The thermoelectric performance of organic semiconductors is commonly evaluated by the thermoelectric power factor $\alpha^{2} \sigma$. A comparison of the different MB doped polymers revealed that their thermoelectric power factor follows the trend of $\alpha^{2} \sigma \propto \sigma^{1 / 2}$ proposed by Glaudell et al. (Figure 5; see Figure $\mathrm{S} 6$ in the Supporting Information). ${ }^{[22]}$

\section{Conclusions}

We have demonstrated that a large palette of semiconducting polymers with an ionization efficiency $\mathrm{IE}_{\text {polymer }}>5.3 \mathrm{eV}$ can

Table 1. Charge-carrier density $N_{\nu}^{u V / V i s}$, electrical conductivity $\sigma$, charge-carrier mobility $\mu$, Seebeck coefficient $\alpha$, and thermoelectric power factor $\alpha^{2} \sigma$ of PDPP-3T doped by immersing polymer films into solutions of $\mathrm{MB}$ in $\mathrm{AcN}: \mathrm{CHCl}_{3}$ (see Experimental section for details).

\begin{tabular}{|c|c|c|c|c|}
\hline$N_{\nu}\left[10^{26} \mathrm{~m}^{-3}\right]$ & $\sigma\left[\mathrm{S} \mathrm{cm}^{-1}\right]$ & $\mu\left[\mathrm{cm}^{2} \mathrm{~V}^{-1} \mathrm{~s}^{-1}\right]$ & $\alpha\left[\mu \vee \mathrm{K}^{-1}\right]$ & $\alpha^{2} \sigma\left[\mu \mathrm{W} \mathrm{m}^{-1} \mathrm{~K}^{-2}\right]$ \\
\hline $0.7 \pm 0.1$ & $0.10 \pm 0.01$ & $0.009 \pm 0.001$ & $220 \pm 2$ & $0.5 \pm 0.1$ \\
\hline $1.6 \pm 0.2$ & $3.6 \pm 0.4$ & $0.14 \pm 0.02$ & $145 \pm 2$ & $7.5 \pm 0.9$ \\
\hline $2.7 \pm 0.3$ & $22 \pm 2$ & $0.51 \pm 0.07$ & $50 \pm 2$ & $5.5 \pm 0.8$ \\
\hline
\end{tabular}


ADVANCED
SCIENCE NEWS

ADVANCED

www.advancedsciencenews.com

MATERIALS

www.advelectronicmat.de
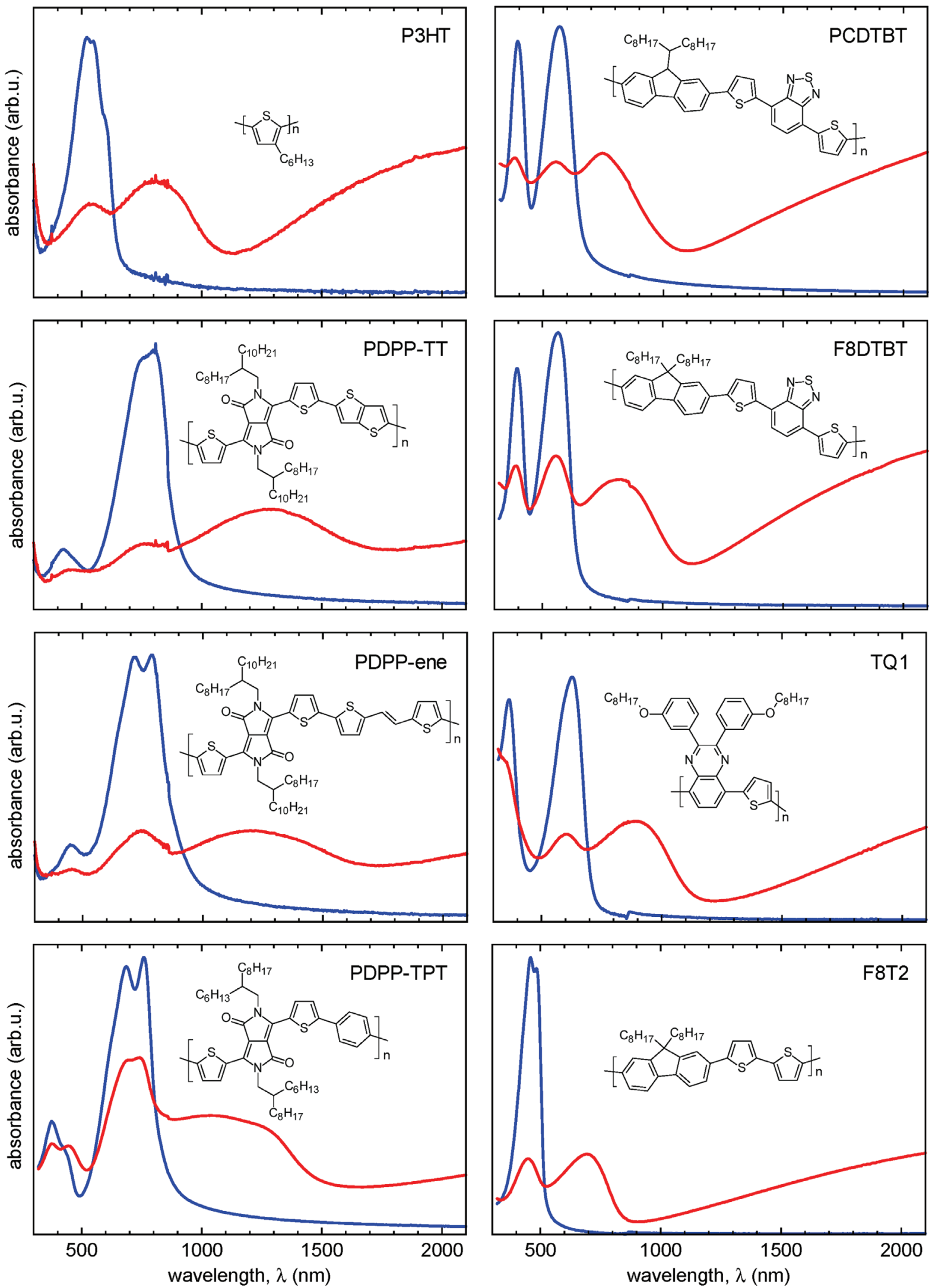

Figure 4. Chemical structures of different polymers and corresponding UV/Vis absorption spectra of thin films in their undoped form (blue) and upon sequential doping with $M B$ (red).

Adv. Electron. Mater. 2020, 6, 2000249

2000249 (5 of 8$)$

(c) 2020 The Authors. Published by WILEY-VCH Verlag GmbH \& Co. KGaA, Weinheim 
Table 2. Chemical structure, number- and weight-average molecular weight, $M_{n}$ and $M_{w}$, ionization energy IE, and conductivity $\sigma$ of polymers sequentially doped by spin-casting solutions of $\mathrm{MB}$ in $\mathrm{AcN}: \mathrm{CHCl}_{3}$ onto polymer films, or in case of PDPP-3T and $\mathrm{P} 3 \mathrm{HT}$ by immersing polymer films into solutions of $\mathrm{MB}$ in $\mathrm{ACN}: \mathrm{CHCl}_{3}$ (see Experimental section for details).

\begin{tabular}{lcccc}
\hline Polymer & $\begin{array}{c}M_{n} \\
{\left[\mathrm{~kg} \mathrm{~mol}^{-1}\right]}\end{array}$ & $\begin{array}{c}M_{w} \\
{\left[\mathrm{~kg} \mathrm{~mol}^{-1}\right]}\end{array}$ & $\begin{array}{c}\mathrm{IE} \\
{[\mathrm{eV}]}\end{array}$ & $\begin{array}{c}\sigma \\
{\left[\mathrm{S} \mathrm{cm}^{-1}\right]}\end{array}$ \\
\hline PDPP-3T & 83 & 178 & $5.4^{\mathrm{a})}$ & $40 \pm 11$ \\
PDPP-TPT & 20 & 28 & $5.4^{\mathrm{a})}$ & $7 \pm 1$ \\
PDPP-TT & 60 & 163 & $5.4^{\mathrm{a})}$ & $55 \pm 6$ \\
PDPP-ene & 14 & 31 & $5.2^{\mathrm{a})}$ & $101 \pm 10$ \\
PCDTBT & 42 & 78 & $5.4^{\mathrm{a})}$ & $76 \pm 9$ \\
F8DTBT & 15 & 45 & $5.4^{\mathrm{a})}$ & $41 \pm 4$ \\
TQ1 & 51 & 150 & $5.5^{\mathrm{a})}$ & $43 \pm 7$ \\
P3HT & 24 & 58 & $5.1^{\mathrm{a})}$ & $26 \pm 3$ \\
MDMO-PPV & 85 & 437 & $5.4^{\mathrm{b})}$ & $0.10 \pm 0.03$ \\
MEH-PPV & 105 & 340 & $5.3^{\mathrm{b})}$ & $6 \pm 1$ \\
PCPDTBT & 30 & 42 & $5.3^{\mathrm{b})}$ & $0.03 \pm 0.01$ \\
F8T2 & 24 & 58 & $5.5^{\mathrm{a})}$ & $27 \pm 3$ \\
PBDB-T & 17 & 63 & $5.3^{\mathrm{b})}$ & $21 \pm 3$ \\
PTB7 & 34 & 82 & $5.1^{\mathrm{b})}$ & $1.0 \pm 0.2$ \\
F8BT & 33 & 217 & $5.9^{\mathrm{b})}$ & - \\
\hline
\end{tabular}

a) Taken from supplier; b) Measured by cyclic voltammetry; IUPAC names of all polymers are given in the Supporting Information.

be efficiently doped with Magic Blue, which makes Magic Blue an attractive and cost-efficient alternative to commonly used strong redox dopants. The doped polymer films displayed conductivities ranging from $10^{-2}$ to $10^{2} \mathrm{~S} \mathrm{~cm}^{-1}$ and thermoelectric power factors between $10^{-1}$ and $10^{1} \mu \mathrm{W} \mathrm{m} \mathrm{m}^{-1} \mathrm{~K}^{-2}$. For one

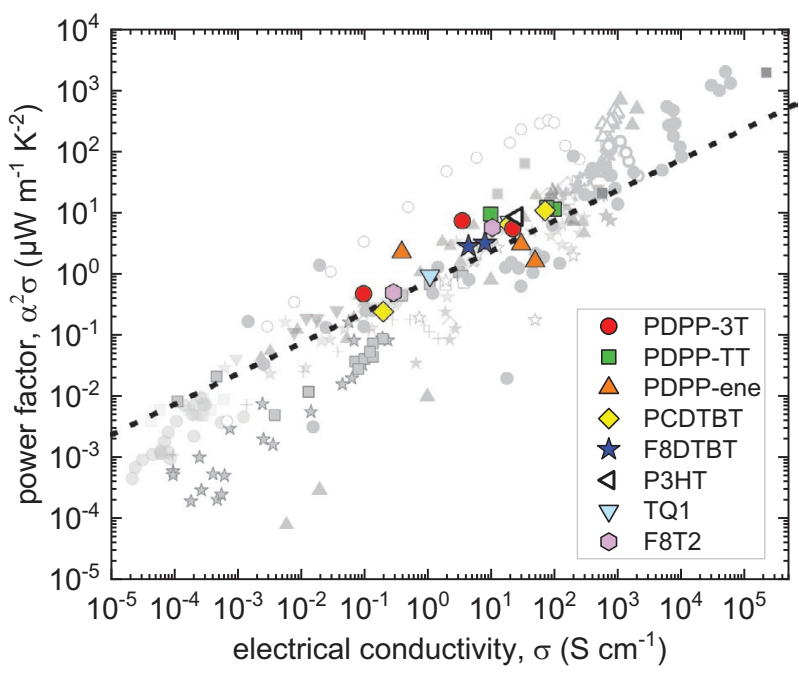

Figure 5. Thermoelectric power factor $\alpha^{2} \sigma$ as a function of the conductivity $\sigma$ of MB doped polymers (colored datapoints) and literature values of p-type materials (grey datapoints; see refs. ${ }^{[23,49]}$ for references used to construct this plot); the dashed line represents the empirical trend $\alpha^{2} \sigma \propto \sigma^{1 / 2}$ proposed by Glaudell et al.[22] polymer, PDPP-3T, we evaluated the charge-carrier density both by EPR as well as a combination of spectroelectrochemistry and chronoamperometry, and find values in the range of $10^{26} \mathrm{~m}^{-3}$, which are typical for highly doped conjugated polymers.

\section{Experimental Section}

Materials: PCDTBT, F8DTBT, PCPDTBT, F8T2, F8BT, and P3HT (regioregularity $\approx 88 \%$ ) were purchased from Solaris. PTB7, PBDB-T, PDPP-3T, and PDPP-TPT were purchased from Solarmer Ltd. Magic Blue, F4TCNQ, MDMO-PPV, MEH-PPV, and anhydrous acetonitrile were purchased from Sigma Aldrich. Chlorobenzene and chloroform were purchased from VWR. All commercial polymers, solvents and the Magic Blue dopant were used as received and without further purification. The synthesis of TQ1 was described elsewhere. ${ }^{[50]}$

Synthesis of PDPP-TT and PDPP-ene: Unless otherwise stated, all reactions were performed under nitrogen atmosphere. All chemicals and solvents were purchased from Sigma-Aldrich and were used as received, except for 2,5-bis(trimethylstannyl)thieno[3,2-b]thiophene which was purchased from Solarmer and recrystallized from ethanol prior to use. (E)-1,2-bis (5-(trimethylstannyl)thiophen-2-yl)ethane ${ }^{[51]}$ and 3,6-bis (5bromothiophen-2-yl)-2,5-bis (2-octyldodecyl)-2,5-dihydropyrrolo[3,4-c] pyrrole-1,4-dione were synthesized according to literature procedures. ${ }^{[52]}$

Standard polymerization procedure for PDPP-TT and PDPP-ene: To a 2-necked round-bottom flask equipped with condenser, the dibromo and distannyl monomers were added (1:1 stoichiometric ratio) as well as $\mathrm{Pd}_{2}(\mathrm{dba})_{3}(2 \mathrm{~mol} \%)$ and $(0 \text {-tol })_{3} \mathrm{P}(8 \mathrm{~mol} \%)$ and $10 \mathrm{~mL}$ toluene (dry, degassed). The resulting mixture was reacted at $70{ }^{\circ} \mathrm{C}$ under stirring for 2-48 hours. The obtained dark green viscous solution was subsequently poured into methanol, the green precipitate collected via filtration and redissolved in $\mathrm{CHCl}_{3}$ at $60^{\circ} \mathrm{C}$. After dissolution, a saturated aqueous solution of sodium diethyl dithiocarbamate dihydrate was added and the mixture stirred vigorously for 1 hour at $60^{\circ} \mathrm{C}$. The organic phase was separated, exhaustively washed with deionized water, concentrated in vacuo, precipitated in methanol after which the polymer was collected by filtration. The polymer was then extracted with methanol, diethyl ether, acetone and finally recovered from the thimble with $\mathrm{CHCl}_{3}$. The chloroform solution was concentrated in vacuo, the polymers precipitated in methanol, collected by filtration and vacuum-dried to afford the DPP-based polymers as dark green solids. ${ }^{1} \mathrm{H}-\mathrm{NMR}$ spectrum of PDPP-ene were measured on an automated Agilent (Varian) MR $400 \mathrm{MHz}$ spectrometer (equipped with "one-probe") with $\mathrm{CDCl}_{3}$ as the solvent (Figure S7, Supporting Information). The peak values were calibrated relative to the solvent signal. In case of PDPP-TT, a meaningful ${ }^{1} \mathrm{H}$-NMR spectrum could not be recorded.

Sample Preparation: Polymers were dissolved in chlorobenzene at $5 \mathrm{~g} \mathrm{~L}^{-1}$ at $80^{\circ} \mathrm{C}$, spin-cast (1800 rpm, $500 \mathrm{rpm} \mathrm{s}^{-1}$ ) onto quartz substrates, ITO coated glass or polyethylene terephthalate (PET) film, yielding films with a thickness between 50 and $200 \mathrm{~nm}$ (measured with a KLA Tencor AlphaStep D-100 profilometer). PDPP-TT ( $3 \mathrm{~g} \mathrm{~L}^{-1}$ in chlorobenzene) was the only polymer that could not be spin-cast into homogeneous films and was thus blade-coated onto the substrate, resulting in a film thickness of about $100 \mathrm{~nm}$. Polymer films were sequentially doped with a solution of 0.45 or $0.9 \mathrm{~g} \mathrm{~L}^{-1} \mathrm{MB}$ in anhydrous $\mathrm{AcN}: \mathrm{CHCl}_{3}$ (3:1, v:v) by either 1) spin-casting (2000 rpm, $\left.500 \mathrm{rpm} \mathrm{s}^{-1}, 30 \mathrm{~s}\right) 100 \mu \mathrm{L}$ of the solution on top of the films, or 2) immersing films into the solution for different times, ranging between 5 and 60 seconds.

Size Exclusion Chromatography (SEC): SEC was performed on an Agilent PL-GPC 220 Integrated HT-GPC System including Refractive Index Detector, PL-GPC 220 Viscometer, and a PL-GPC 220 Dual Angle LSD columns: 3x PLgel 10um MIXED-B LS. The eluent was 1,2,4-trichlorobenzene. The operating temperature was $150{ }^{\circ} \mathrm{C}$, and the dissolution time was $2 \mathrm{~h}$. The concentration of the samples was $0.5 \mathrm{~g} \mathrm{~L}^{-1}$, which were filtered (filter: $0.45 \mu \mathrm{m}$ ) prior to analysis. The molecular weights were calculated according relative calibration with polystyrene standards. 
UV/Vis Absorption Spectroscopy: UV/Vis absorption spectroscopy of polymer films on quartz glass (unless stated otherwise) was performed with a PerkinElmer Lambda 1050 spectrophotometer.

Electron Paramagnetic Resonance (EPR) Spectroscopy: A PDPP-3T sample for EPR was prepared by spin-coating a $126 \mathrm{~nm}$ thin film on a PET substrate, which was cut to a size of $3 \mathrm{~mm} \times 0.3 \mathrm{~mm}$, and then sealed under nitrogen in a quartz EPR tube. Spectra were recorded at $9.85 \mathrm{MHz}$ with a commercial spectrometer (Bruker EMXplus) using an $X$-band microwave bridge (Bruker EMX PremiumX) and a high-quality cavity (Bruker 4119HS-W1). The magnetic field was calibrated using a $\mathrm{Mn}$ (II) standard with known g-factor. Spin counting was done using Xenon SpinCount (Bruker) by comparing with a standard sample with known number of spins. The thickness of the sample was measured with a KLA Tencor AlphaStep D-100 profilometer.

Electrochemistry: Electrochemical measurements were performed with freshly prepared solutions of tetra- $n$-butylammonium hexafluorophosphate $\left(\mathrm{TBAPF}_{6}\right)$ in dry acetonitrile $(0.1 \mathrm{M})$ using a custom made three-electrode setup in a standard $1 \mathrm{~cm} \times 1 \mathrm{~cm}$ quartz cuvette. Polymer films were spin-cast onto ITO coated glass substrates $(R \approx$ $100 \mathrm{Ohm} \mathrm{sq}{ }^{-1}$ ). The ITO/glass supported polymer film served as the working electrode, a Pt wire $(\varnothing \approx 1 \mathrm{~mm})$ served as the counter electrode and a $\mathrm{Ag}$ wire was used as the pseudo-reference electrode. The potentials were calibrated versus the Ferrocene/Ferrocenium $\left(\mathrm{Fc} / \mathrm{Fc}^{+}\right)$redox couple. Cyclic voltammograms were recorded with a scan rate of $100 \mathrm{mV} \mathrm{s}^{-1}$ using a 650D electrochemical workstation from $\mathrm{CH}$ Instruments. The ionization energies of the polymers were calculated using IE $=5.1 \mathrm{eV}$ $+E_{\text {ox versus } \mathrm{Fc} / \mathrm{Fc}+}$, where $E_{\text {ox versus } \mathrm{Fc} / \mathrm{Fc}+}$ is the oxidation onset versus $\mathrm{Fc} /$ $\mathrm{Fc}^{+}$. The potentiostatic spectroelectrochemistry and chronoamperometry experiments of PDPP-3T were performed inside a PerkinElmer Lambda 1050 spectrophotometer. The thickness of the PDPP-3T film on ITO/ glass was estimated by comparing its absorbance with the absorbance of a PDPP-3T film on glass with known thickness; the outer dimensions of the sample $(0.6 \mathrm{~cm} \times 2.5 \mathrm{~cm})$ were measured using a caliper. For the chronoamperometry measurements we first applied a potential considerably lower than the oxidation onset of the polymer $\left(E<E_{\mathrm{ox}}\right.$, for $30 \mathrm{~s}$ ), to ensure full reduction of the polymer working electrode. Then, a constant positive potential $\left(E>E_{\text {ox }}\right)$ was applied and the transient current was recorded. Once the transient current had fallen back to the steady state a UV/Vis absorption spectrum was recorded. The potentiodynamic spectroelectrochemistry measurement of PDPP-3T was carried out as described previously. ${ }^{[53]}$

Electrical Characterization: The electrical resistivity was measured using a four-point probe setup from Jandel Engineering (cylindrical probe head, RM3000). An SB1000 instrument equipped with a K2000 temperature controller from MMR Technologies was used to measure the Seebeck coefficients. All Seebeck coefficients were measured at $300 \mathrm{~K}$, using a thermal load of $1-2 \mathrm{~K}$ and a constantan wire as an internal reference. Pieces of about $1 \mathrm{~mm} \times 5 \mathrm{~mm}$ were cut from the PET supported samples and mounted on the sample stage using a conducting carbon paint (Ted Pella, Inc., Dag-T-502). The film thickness was measured with a KLA Tencor AlphaStep D-100 profilometer. All electrical characterization was performed under ambient conditions on the same day as the sample preparation and the optical characterization.

\section{Supporting Information}

Supporting Information is available from the Wiley Online Library or from the author.

\section{Acknowledgements}

The authors gratefully acknowledge financial support from the Swedish Research Council through grants no. 2016-06146 and 2018-03824, the Knut and Alice Wallenberg Foundation through a Wallenberg Academy Fellowship, and the European Research Council (ERC) under grant agreement no. 637624. The authors thank Anders Mårtensson (Chalmers) for carrying out the SEC experiments. T.B. thanks Christopher W. M. Kay (Saarbrücken) for support. C.M. and S.L. thank the Carl-Zeiss-Foundation for funding within the IQST Stuttgart /UIm.

\section{Conflict of Interest}

The authors declare no conflict of interest.

\section{Keywords}

charge-carrier density, chemical doping, conjugated polymers, electrochemical doping, magic blue, organic thermoelectrics

Received: March 9, 2020

Revised: May 20, 2020

Published online: July 15, 2020

[1] M. Fahlman, S. Fabiano, V. Gueskine, D. Simon, M. Berggren, X. Crispin, Nat. Rev. Mater. 2019, 4, 627.

[2] A. Lund, N. M. van der Velden, N. K. Persson, M. M. Hamedi, C. Müller, Mater. Sci. Eng., R 2018, 126, 1.

[3] J. C. Yang, J. Mun, S. Y. Kwon, S. Park, Z. N. Bao, S. Park, Adv. Mater. 2019, 31, 1904765.

[4] B. H. Wang, A. Facchetti, Adv. Mater. 2019, 31, 1901408.

[5] B. Lüssem, C. M. Keum, D. Kasemann, B. Naab, Z. N. Bao, K. Leo, Chem. Rev. 2016, 116, 13714.

[6] O. Bubnova, X. Crispin, Energy Environ. Sci. 2012, 5, 9345.

[7] B. Russ, A. Glaudell, J. J. Urban, M. L. Chabinyc, R. A. Segalman, Nat. Rev. Mater. 2016, 1, 16050.

[8] R. Kroon, D. A. Mengistie, D. Kiefer, J. Hynynen, J. D. Ryan, L. Y. Yu, C. Müller, Chem. Soc. Rev. 2016, 45, 6147.

[9] J. Rivnay, S. Inal, A. Salleo, R. M. Owens, M. Berggren, G. G. Malliaras, Nat. Rev. Mater. 2018, 3, 17086.

[10] S. Tang, L. Edman, Top. Curr. Chem. 2016, 374, 40.

[11] D. Kiefer, R. Kroon, A. I. Hofmann, H. D. Sun, X. J. Liu, A. Giovannitti, D. Stegerer, A. Cano, J. Hynynen, L. Y. Yu, Y. D. Zhang, D. Q. Nai, T. F. Harrelson, M. Sommer, A. J. Moule, M. Kemerink, S. R. Marder, I. McCulloch, M. Fahlman, S. Fabiano, C. Müller, Nat. Mater. 2019, 18, 149.

[12] I. Salzmann, G. Heimel, M. Oehzelt, S. Winkler, N. Koch, Acc. Chem. Res. 2016, 49, 370.

[13] I. E. Jacobs, A. J. Moulé, Adv. Mater. 2017, 29, 1703063.

[14] I. E. Jacobs, E. W. Aasen, J. L. Oliveira, T. N. Fonseca, J. D. Roehling, J. Li, G. W. Zhang, M. P. Augustine, M. Mascal, A. J. Moulé, J. Mater. Chem. C 2016, 4, 3454.

[15] J. Hynynen, D. Kiefer, L. Y. Yu, R. Kroon, R. Munir, A. Amassian, M. Kemerink, C. Müller, Macromolecules 2017, 50, 8140.

[16] E. Lim, K. A. Peterson, G. M. Su, M. L. Chabinyc, Chem. Mater. 2018, 30, 998.

[17] H. Mendez, G. Heimel, S. Winkler, J. Frisch, A. Opitz, K. Sauer, B. Wegner, M. Oehzelt, C. Rothel, S. Duhm, D. Tobbens, N. Koch, I. Salzmann, Nat. Commun. 2015, 6.

[18] D. T. Scholes, P. Y. Yee, J. R. Lindemuth, H. Kang, J. Onorato, R. Ghosh, C. K. Luscombe, F. C. Spano, S. H. Tolbert, B. J. Schwartz, Adv. Funct. Mater. 2017, 27, 1702654.

[19] K. E. Watts, B. Neelamraju, E. L. Ratcliff, J. E. Pemberton, Chem. Mater. 2019, 31, 6986.

[20] K. Kang, S. Watanabe, K. Broch, A. Sepe, A. Brown, I. Nasrallah, M. Nikolka, Z. P. Fei, M. Heeney, D. Matsumoto, K. Marumoto, H. Tanaka, S. Kuroda, H. Sirringhaus, Nat. Mater. 2016, 15, 896. 
[21] S. N. Patel, A. M. Glaudell, K. A. Peterson, E. M. Thomas, K. A. O'Hara, E. Lim, M. L. Chabinyc, Sci. Adv. 2017, 3, 1700434.

[22] A. M. Glaudell, J. E. Cochran, S. N. Patel, M. L. Chabinyc, Adv. Energy Mater. 2015, 5, 1401072.

[23] D. Beretta, N. Neophytou, J. M. Hodges, M. G. Kanatzidis, D. Narducci, M. Martin-Gonzalez, M. Beekman, B. Bakle, G. Cerretti, W. Tremel, A. Zevalkink, A. I. Hofmann, C. Müller, B. Dörling, M. Campoy-Quiles, M. Caironi, Mater. Sci. Eng, R 2019, 38, 100501.

[24] Y. Karpov, T. Erdmann, M. Stamm, U. Lappan, O. Guskova, M. Malanin, I. Raguzin, T. Beryozkina, V. Bakulev, F. Gunther, S. Gemming, G. Seifert, M. Hambsch, S. Mannsfeld, B. Voit, A. Kiriy, Macromolecules 2017, 50, 914.

[25] J. Saska, G. Gonel, Z. I. Bedolla-Valdez, S. D. Aronow, N. E. Shevchenko, A. S. Dudnik, A. J. Moulé, M. Mascal, Chem. Mater. 2019, 31, 1500

[26] Y. B. Qi, T. Sajoto, S. Barlow, E. G. Kim, J. L. Bredas, S. R. Marder, A. Kahn, J. Am. Chem. Soc. 2009, 131, 12530

[27] Z. M. Liang, Y. D. Zhang, M. Souri, X. Y. Luo, A. M. Boehm, R. P. Li, Y. Zhang, T. R. Wang, D. Y. Kim, J. G. Mei, S. R. Marder, K. R. Graham, J. Mater. Chem. A 2018, 6, 16495.

[28] J. Hynynen, E. Järsvall, R. Kroon, Y. D. Zhang, S. Barlow, S. R. Marder, M. Kemerink, A. Lund, C. Müller, ACS Macro Lett. 2019, 8, 70.

[29] Y. Karpov, T. Erdmann, I. Raguzin, M. Al-Hussein, M. Binner, U. Lappan, M. Stamm, K. L. Gerasimov, T. Beryozkina, V. Bakulev, D. V. Anokhin, D. A. Ivanov, F. Gunther, S. Gemming, G. Seifert, B. Voit, R. Di Pietro, A. Kiriy, Adv. Mater. 2016, 28, 6003.

[30] C. Francis, D. Fazzi, S. B. Grimm, F. Paulus, S. Beck, S. Hillebrandt, A. Pucci, J. Zaumseil, J. Mater. Chem. C 2017, 5, 6176.

[31] J. Li, I. Duchemin, O. M. Roscioni, P. Friederich, M. Anderson, E. Da Como, G. Kociok-Kohn, W. Wenzel, C. Zannoni, D. Beljonne, X. Blase, G. D'Avino, Mater. Horiz. 2019, 6, 107

[32] S. Y. Zhang, H. M. Hill, K. Moudgil, C. A. Richter, A. R. H. Walker, S. Barlow, S. R. Marder, C. A. Hacker, S. J. Pookpanratana, Adv. Mater. 2018, 30, 1802991.

[33] A. E. Mansour, M. M. Said, S. Dey, H. L. Hu, S. Y. Zhang, R. Munir, Y. D. Zhang, K. Moudgil, S. Barlow, S. R. Marder, A. Amassian, Adv. Funct. Mater. 2017, 27, 1602004.
[34] R. P. Veregin, J. R. Harbour, J. Phys. Chem. 1990, 94, 6231.

[35] A. Yamamori, C. Adachi, T. Koyama, Y. Taniguchi, Appl. Phys. Lett. 1998, 72, 2147.

[36] C. Ganzorig, M. Fujihira, Appl. Phys. Lett. 2000, 77, 4211.

[37] P. Reinold, K. Bruchlos, S. Ludwigs, Polym. Chem. 2017, 8, 7351.

[38] Y. M. Gross, D. Trefz, C. Dingler, D. Bauer, V. Vijayakumar, V. Untilova, L. Biniek, M. Brinkmann, S. Ludwigs, Chem. Mater. 2019, 31, 3542.

[39] C. Malacrida, A. H. Habibi, S. Gmez-Valenzuelak, I. Lenko, P. S. Marqus, A. Labrunie, J. Grolleau, J. T. L. Navarrete, M. C. R. Delgado, C. Cabanetos, P. Blanchard, S. Ludwigsa, Chem. Electrochem. 2019, 6, 4215.

[40] D. E. Stilwell, S. M. Park, J. Electrochem. Soc. 1988, 135, 2497.

[41] I. Enokida, Y. Furukawa, Org. Electron. 2019, 68, 28.

[42] J. Heinze, B. A. Frontana-Uribe, S. Ludwigs, Chem. Rev. 2010, 110, 4724.

[43] E. L. Williams, T. S. Ang, Z. Ooi, P. Sonar, T. T. Lin, W. T. Neo, J. Song, J. Hobley, Polymers 2015, 7, 69.

[44] R. Ghosh, A. R. Chew, J. Onorato, V. Pakhnyuk, C. K. Luscombe, A. Salleo, F. C. Spano, J. Phys. Chem. C 2018, 122, 18048.

[45] M. C. Simoes, K. J. Hughes, D. B. Ingham, L. Ma, M. Pourkashanian, Inorg. Chem. 2017, 56, 7566

[46] P. Pingel, D. Neher, Phys. Rev. B 2013, 87, 115209.

[47] C. C. Wang, D. T. Duong, K. Vandewal, J. Rivnay, A. Salleo, Phys. Rev. B 2015, 91.

[48] Y. N. Li, P. Sonar, L. Murphy, W. Hong, Energy Environ. Sci. 2013, 6 , 1684.

[49] V. Vijayakumar, Y. H. Zhong, V. Untilova, M. Bahri, L. Herrmann, L. Biniek, N. Leclerc, M. Brinkmann, Adv. Energy Mater. 2019, 9, 1900266.

[50] A. Diaz de Zerio Mendaza, J. Bergqvist, O. Backe, C. Lindqvist, R. Kroon, F. Gao, M. R. Andersson, E. Olsson, O. Inganäs, C. Müller, J. Mater. Chem. A 2014, 2, 14354.

[51] J. Choi, K. H. Kim, H. Yu, C. Lee, H. Kang, I. Song, Y. Kim, J. H. Oh, B. J. Kim, Chem. Mater. 2015, 27, 5230.

[52] Y. N. Li, S. P. Singh, P. Sonar, Adv. Mater. 2010, 22, 4862.

[53] K. Bruchlos, D. Trefz, A. Hamidi-Sakr, M. Brinkmann, J. Heinze, A. Ruff, S. Ludwigs, Electrochim. Acta 2018, 269, 299. 